\title{
Projeto Escola no Cinema e Clube do Professor
}

Consuelo Ivo ${ }^{1}$

Jornalista especialista em Gestão da Comunicação e editora executiva da revista Comunicação \& Educação.

E-mail: consuelo.ivo@terra.com.br

Resumo: A seção apresenta duas atividades de entretenimento interessantes para professores e alunos. O Projeto Escola no Cinema, que é concebido pelo Circuito Espaço de Cinema, coordenado por Patrícia Durães e Eliane Monteiro. A proposta é oferecer um mergulho cultural através do cinema, em formação permanente de educadores e educandos. O projeto aposta na integração de linguagens, procurando sempre correlacionar áreas do conhecimento em suas propostas. Já o Clube do Professor oferece sessões exclusivas para professores do ensino formal e informal, todos os sábados, nos cinemas da rede Unibanco Arteplex e Espaço Unibanco de Cinema. O objetivo é ampliar o universo cinematográfico do professor, sem o compromisso de um trabalho pedagógico imediato à experiência cinematográfica.

Palavras-chave: cinema, educação, escola, Projeto Escola no Cinema, Clube do Professor.
Abstract: This section introduces two interesting entertainment activities for teachers and students. The Project Escola no Cinema, created by Circuito Espaço de Cinema, which is coordinated by Patrícia Durães and Eliane Monteiro. The proposal is offering a cultural immersion through cinema, as continuing formation of educator and pupils. The project invests in languages integration, always trying to correlate knowledge areas. Meanwhile, the project Clube do Professor offers exclusive sessions for teachers of formal and informal teaching, in the movie theaters belonging to the chains Unibanco Arteplex and Espaço Unibanco de Cinema. Its objective is to expand the teacher's movie universe, without the commitment of a pedagogic work immediate to the movie experience.

Keywords: cinema, education, school, Project Escola no Cinema, Clube do Professor

\section{ESCOLA NO CINEMA}

O Projeto Escola no Cinema ${ }^{2}$ (http://www.escolanocinema.com.br) iniciou suas atividades em 1985, no Rio de Janeiro, estendendo-se para São Paulo em 1993. É um projeto do Circuito Espaço de Cinema, coordenado desde sua criação por Patrícia Durães e Eliane Monteiro. A proposta é oferecer "um mergulho cultural através do cinema, em formação permanente de educadores e educandos", revelam as coordenadoras.

1. Com a colaboração de Renata Lima, assessora de imprensa da F\&M Procultura (www.fmprocultura. com.br).

2. Disponível em: <http:// www.escolanocinema. com.br>. 
comunicação \& educação • Ano XIV • Número 1 • jan/abr 2009

A atividade não se limita a apenas exibir um filme. Com ele realizam-se oficinas, debates e atividades complementares que ampliam seu conteúdo e aprofundam o universo retratado. $\mathrm{O}$ projeto aposta na integração de linguagens, procurando sempre correlacionar áreas do conhecimento em suas propostas.

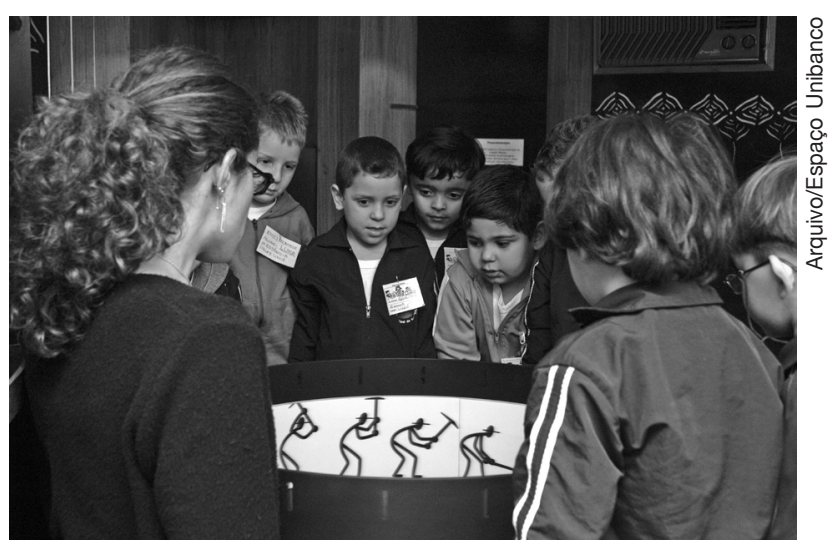
A intenção, segundo suas criadoras, é buscar, com o auxílio de diversas formas de expressão, contribuir para a formação de um espectador crítico e atuante na sociedade.

Alguns eventos podem ser realizados fora do eixo Rio-São Paulo, como em Porto Alegre, Curitiba, Fortaleza, Juiz de Fora, com comunicação prévia por boletins ou através do site do Projeto.

\section{Como participar}

1) Indicação de filmes em cartaz.

Ocorrem através de reservas para as sessões da programação diária dos cinemas em que o projeto atua.

2) Indicação de filmes fora do circuito de exibição.

São sessões especiais no horário alternativo. O professor escolhe o filme conforme o interesse de seu grupo.

3) Eventos.

Exibição de filmes acompanhada de atividades complementares, integrando várias linguagens artísticas às diversas áreas do conhecimento. As propostas são desenvolvidas através de oficinas, exposições, palestras, instalações ou perfor-

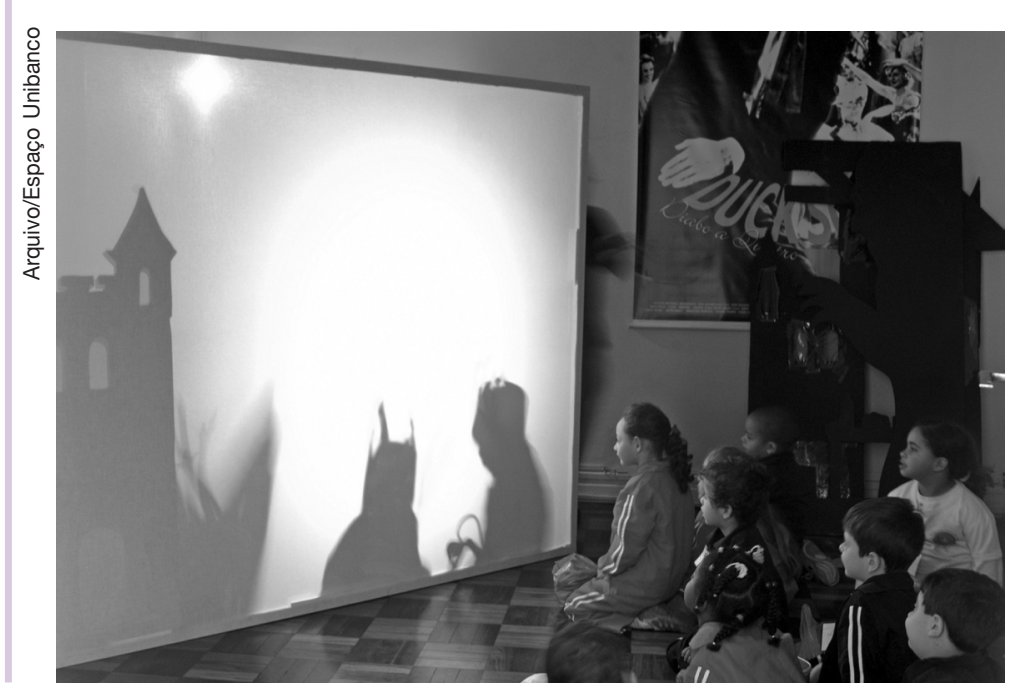
mances. São oferecidas sessões especiais para professores, para conhecimento prévio dos filmes. 
Projeto Escola no Cinema e Clube do Professor - Consuelo Ivo

\section{Como fazer as reservas}

\section{Filmes em cartaz}

Para fazer reservas nas sessões diárias, abertas ao público, é preciso:

- acompanhar nos jornais diários a programação de filmes e horários (muda sempre às sextas-feiras);

- mobilizar os alunos, com antecedência, para definição do número de reservas. É possível reservar, aproximadamente, 1/3 da lotação das salas;

- ligar e reservar com antecedência de uma semana;

- as reservas terão validade até 20 minutos antes do início da sessão;

- ligar para confirmar ou cancelar a sessão um dia antes de sua realização.

O valor do ingresso é meia-entrada.

\section{Filmes exclusivos}

Para reservas nos horários alternativos (entre $9 \mathrm{~h}$ e $13 \mathrm{~h}$ ) é preciso:

- o professor escolher o filme conforme a proposta. O Projeto também poderá indicar um filme de acordo com os conteúdos que serão trabalhados;

- ligar com antecedência de quinze dias para solicitar o filme, saber da disponibilidade de cópia e agendar;

- mobilizar os alunos, com antecedência, para definição do número de reservas. É necessário o mínimo de cem alunos para viabilizar a sessão;

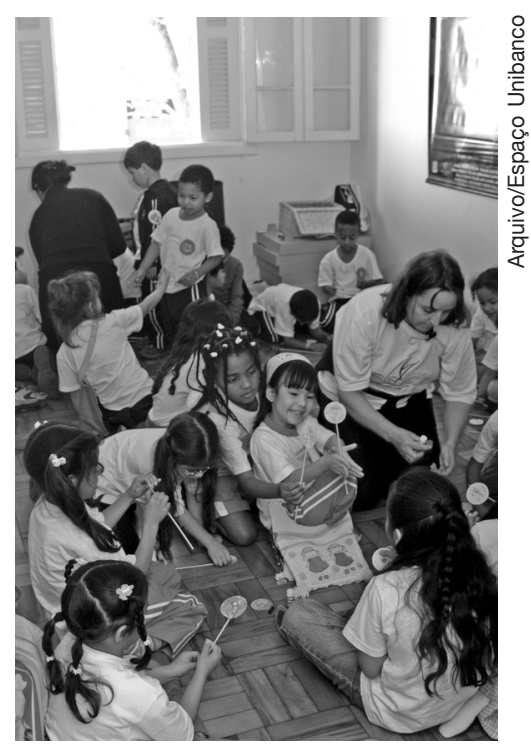

- ligar para confirmar sessão, data e número de alunos com dois dias de antecedência;

- ligar para cancelar a sessão quatro dias antes de sua realização.

$\mathrm{O}$ valor do ingresso é com preços promocionais.

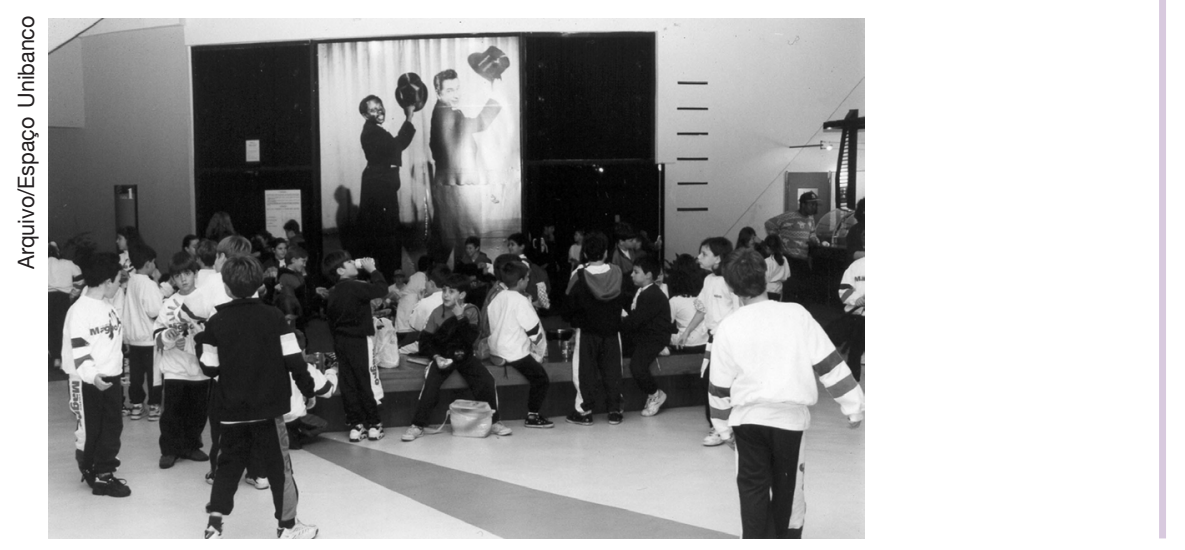


comunicação \& educação • Ano XIV • Número 1 • jan/abr 2009

\section{Eventos}

Para essa forma de atendimento, é necessário aguardar uma correspondência específica, com as informações sobre o filme, as atividades complementares e os procedimentos para a participação das escolas e professores.

\section{Importante}

$\mathrm{O}$ projeto estende seu atendimento às associações beneficentes e outras entidades que atuam nas áreas educacional, social e cultural, com 30 ingressos promocionais (preço simbólico) nas sessões diárias do cinema (de segunda a quinta-feira), mediante reserva. Dentro dos procedimentos para filmes exclusivos, o projeto pode atender, além das escolas, a outros grupos de estudo e/ou trabalho que queiram utilizar a linguagem cinematográfica em suas atividades.

Para maiores informações:

São Paulo - Tel.: (11) 3266-5115, com Patrícia ou Ivete.

Santos - Tel.: (13) 3284-4044, com Érica ou Raphael.

Rio de Janeiro - Tel.: (21) 2559-8768, com Lili ou Marília.

Porto Alegre - Tel.: (51) 3341-0621, com Carla.

Tubarão (SC) - Tel.: (48) 3621-5288, com Cláudia.

Fortaleza, Curitiba e Juiz de Fora - ligar para São Paulo: Tel.: (11) 3266-5115.

\section{CLUBE DO PROFESSOR}

São sessões exclusivas para professores do ensino formal e informal, todos os sábados, nos cinemas da rede Unibanco Arteplex e Espaço Unibanco de Cinema. A programação aposta na diversidade, incluindo obras de todas as nacionalidades, filmes inéditos, clássicos e do circuito comercial. O objetivo é ampliar o universo cinematográfico do professor, visando ao prazer de ver um bom filme em uma sala especializada, sem o compromisso de um trabalho pedagógico imediato a tal experiência.

A programação deve ser acompanhada através de jornais, dos folhetos distribuídos nos cinemas ou do site <http://www.escolanocinema.com.br>. Os organizadores ressaltam a importância de verificar, além da programação da semana, o horário, passível de eventuais alterações, e a indicação etária do filme - detalhe muito importante, já que não será liberada a entrada de crianças e bebês em filmes destinados ao público adulto.

A entrada é gratuita para o portador da carteirinha do Clube do Professor e um acompanhante. É necessário apresentar o RG com a carteirinha. O acompanhante deverá estar presente para obter a sua cortesia.

Para associar-se é simples: no horário de funcionamento do cinema, basta apresentar um comprovante profissional e retirar a ficha cadastral na bilheteria, preencher os dados e entregar no mesmo local. É preciso anexar uma cópia 
Projeto Escola no Cinema e Clube do Professor - Consuelo Ivo

do documento apresentado para o cadastro. No caso de inscrição pelo site, enviar por fax ou e-mail o comprovante. No prazo de dez dias a carteirinha estará pronta e disponível para retirada durante seis meses; após este período, será cancelada.

A carteirinha do Clube do Professor dá direito a $50 \%$ de desconto em todas as sessões, de segunda a sexta-feira, no Unibanco Arteplex e Espaço Unibanco de Cinema, e também dá acesso ao Clube do Professor de outras cidades.

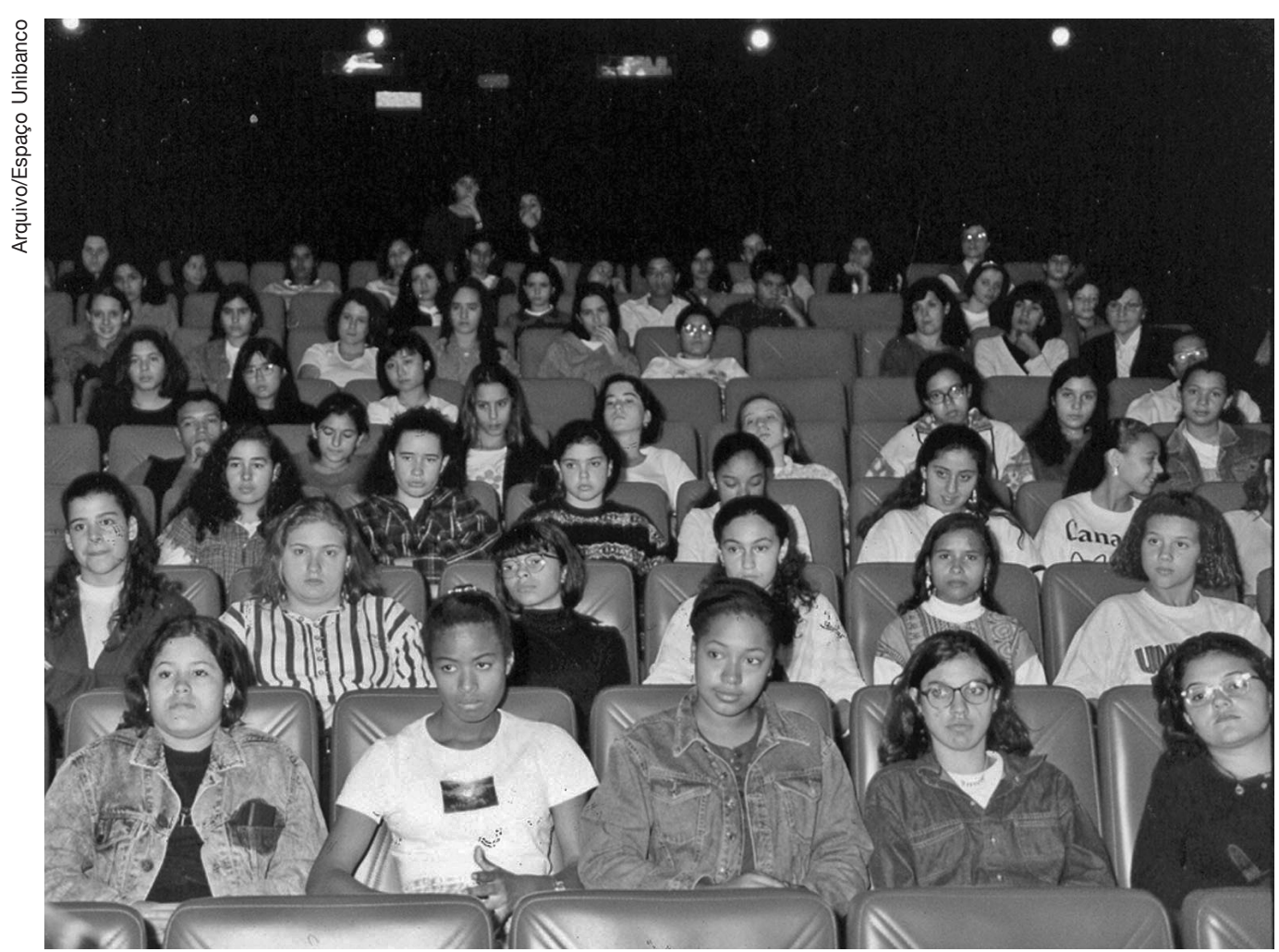

\section{Informações específicas de cada cidade}

\section{São Paulo}

Unibanco Arteplex - Shopping Frei Caneca - Rua Frei Caneca, 569 - 3o piso Início da sessão: 11 horas

Informações: Patrícia e Ivete

Tel.: (11) 3266-5115 - E-mail: saopaulo@escolanocinema.com.br

Cine Bombril - Rua Padre João Manoel, 100 - Loja 1 - Conjunto Nacional Início da sessão: 12 horas

Informações: Patrícia e Ivete

Tels.: (11) 3596-5115 ou (11) 3285-3696 - E-mail: saopaulo@escolanocinema.com.br 
comunicação \& educação • Ano XIV • Número 1 • jan/abr 2009

\section{Santos}

Espaço Unibanco Miramar - Shopping Miramar - Av. Marechal Floriano Peixoto, 44 - Gonzaga

Início da sessão: 11 horas

Informações: Érica e Rafael

Tel.: (13) 3284-4044 - E-mail: santos@escolanocinema.com.br

Rio de Janeiro

Espaço Rio Design - Shopping Rio Design Center - Avenida das Américas, 7777 - Lojas 315 a 317 - Barra da Tijuca

Início da sessão: 13 horas

Unibanco Arteplex - Praia de Botafogo, 316 - Botafogo

Início da sessão: 11 horas

Informações: Lili e Marília

Tel: (21) 2559-8768 - E-mail: riodejaneiro@escolanocinema.com.br

Juiz de Fora

Espaço Palace de Cinema - Rua Halford - Centro

Início da sessão: 13 horas

Informações: Ricardo

Tel.: (32) 3214-3979 - E-mail:juizdefora@escolanocinema.com.br

(Obs.: as sessões estão temporariamente suspensas)

Curitiba

Unibanco Arteplex - Shopping Crystal Plaza - Rua Comendador

Araújo, 731 - Batel

Início da sessão: 13 horas

Informações: Jonatas

Tel.: (41) 3224-3251 - E-mail: curitiba@escolanocinema.com.br

Porto Alegre

Unibanco Arteplex - Shopping Bourbon Country - Av. Túlio de

Rose, $80-2^{\circ}$ piso

Início da sessão: 11 horas

Informações: Carla

Tel.: (51) 3341-0621 - e-mail: portoalegre@escolanocinema.com.br

Fortaleza

Espaço Unibanco Dragão do Mar - Centro Cultural Dragão do Mar -

Rua Dragão do Mar, 41 - Centro

Início da sessão: horários variados

Informações: Lucineide

Tel.: (85) 3219-2641 - E-mail: fortaleza@escolanocinema.com.br 